\title{
AN INTEGRATED SYSTEMS APPROACH TO RISK MANAGEMENT WITHIN A TECHNOLOGY-DRIVEN INDUSTRY, USING THE DESIGN STRUCTURE MATRIX AND FUZZY LOGIC
}

\author{
W.F. Barkhuizen ${ }^{1}$, J .H.C. Pretorius ${ }^{2} \&$ L. Pretorius ${ }^{3 *}$ \\ ${ }^{1,2}$ University of Johannesburg, South Africa \\ ${ }^{3}$ Graduate School of Technology Management \\ University of Pretoria, South Africa \\ leon.pretorius@up.ac.za
}

\begin{abstract}
Risk interactions exist within a system and its sub-systems, between functional and physical elements in various dimensions such as spatial interaction, information exchange, material transfer, and energy exchange. These interactions are of a multi-dimensional complexity, and thus are not sufficiently interpreted using conventional management tools. Alternative system representation and analysis techniques are proposed - in particular the design structure matrix (DSM) and fuzzy logic thinking - to quantify the risk management effort necessary to deal with uncertain and imprecise interactions. A cement grinding plant case study is used to elaborate on the risk management methodology
\end{abstract}

\section{OPSOMMING}

Risiko-interaksies bestaan binne 'n stelsel en sy sub-stelsels, tussen funksionele en fisiese elemente. Hierdie interaksies kan gekwantifiseer word in 'n ruimtelike, inligting-uitruiling, materiaal-oordrag of energie-uitruiling raamwerk. Die interaksies is van 'n multidimensionele kompleksiteit, en word nie effektief geïnterpreteer deur middel van konvensionele beheermetodes nie. Alternatiewe stelselvoorstelling- en analiseringstegnieke kan gebruik word om die sisteeminteraksies te visualiseer. Die Ontwerp Struktuur Matriks ('design structure matrix'), en Wasige Logika ('Fuzzy Logic') word ingespan om hierdie interaksies voor te stel en eenvoudig te kwantifiseer. 'n Sementaanleggevallestudie word gebruik om die risikobestuurmetodologie op die proef te stel.

* Corresponding author

\# This article is an extended version of a paper presented at the 2011 ISEM conference. 


\section{INTRODUCTION AND RESEARCH AIM}

"In the old days, the tools of farming, manufacture, business management, and communication were simple. Breakdowns were frequent, but repairs could be made without calling the plumber, the electrician, the computer scientist - or the accountant and the investment advisors. Today, however, the tools we use are complex, and breakdowns can be catastrophic, with far reaching consequences. We must be constantly aware of the likelihood of malfunctions and errors." [1]

For the technology-driven industry, innovation occurs where market needs and technology knowhow overlap [2]. "Innovation is the act of introducing something new." [3] When companies are competing on the technology playground they need to be innovative. According to Byrd \& Brown [3], the 'act of introducing' relates to risk taking, and the 'new' relates to creativity, and therefore these concepts, creativity and risk taking in combination, are what innovation is all about. Risk management has become one of the greatest challenges of the $21^{\text {st }}$ century $[1,4]$, and one of the main components in innovation and the technology-driven industry, intensifying the need for a systematic approach to managing uncertainties.

\section{Innovation f (Creativity x Risk Taking)}

To think creatively we have to realise that "we can't solve problems by using the same kind of thinking we used when we created them" (Einstein [6]). Being creative and taking risks is one of the ways that innovation can be realised [5, 7].

Localised and reactive risk management techniques will not be effective in today's globalised high technology industry [8,9]. During the development and design of complex engineering products, the input and teamwork of multiple participants from various backgrounds are required, resulting in complex interactions [10]. Risk interactions exist between the functional and physical elements within such a system and its sub-systems in various dimensions such as spatial interaction, information interaction, etc. The relationships are of a multi-dimensional complexity that cannot be simplified using the standard management tools [11, 12]. Illustrating these risk interactions in a complex system embodies the essence of the research aim addressed in this paper. The research method followed is exploratory in nature, and backed up by a case study of a complex system.

To find a meaningful starting point for the seemingly boundless subject of risk management, the logical approach is to take a step back into the basic definition of risk management. Each of the risk management processes (risk assessment, risk identification, risk analysis, risk evaluation, risk treatment, and risk monitoring and review), and how these processes can be enhanced using the design structure matrix (DSM) and fuzzy logic thinking to address the uncertain, imprecise, and multi-dimensional nature of the interactions between system elements, were explored [13].

The approach to enterprise risk management should be seen as holistic, similar to the total quality management process $[1,4,14,15,17,18]$, providing the opportunity to incorporate risk management during the design process as a concurrent task [19]. The risk management model is developed concurrently (during the design phase) using product development methodologies such as conceptual modelling and prototyping, where ultimately the prototype is tested by means of a case study of a cement grinding section in a cement production process.

The result of the risk management model - and in essence the research presented in this paper - is a clustered DSM providing a visual representation of the system risk areas similar to the methodology used in Finite Element Analysis (FEA) [20,12]. 


\section{APPLICATION OF SYSTEMS ENGINEERING IN RISK MANAGEMENT}

Technical components or systems do not operate in isolation: they are, in general, part of a larger system [21]. For the system to function, it often involves human interaction through input effects (operating, controlling, etc.). The system responds to this interference and provides feedback in the form of effects or signals that result in further actions. A system can therefore be influenced from outside by human intervention, or by intervention from the environment in which it exists [17]. The intervention can have a positive or negative influence on the functionality of the system, and it can trigger undesired side effects, from individual components within the sub-system or from the overall system itself [22]. The combined interrelationship of all these effects has to be carefully considered during the development of technical systems.

One of the ways to approach complex problems is to study the underlying structure of the complex system. Systems thinking embraces holism and creativity to handle complexity, change, and diversity [23]. In the technology-driven industry, people are predominantly technically trained and exhibit a logical, realistic, and rational approach. It still seems, however, that people manage risk intuitively, largely based on their past experience [24]; but risk management is becoming too complex due to its multi-dimensional nature.

According to Van Asset [5], decision-making becomes complex when there is not a single problem but an intertwined web of related problems, when the decision or issue lies across or at the intersection of many disciplines (multi-dimensional), or when the underlying process interacts on different scale levels. The fact that consensus must be reached by a group of experts to lower the uncertainty in a risk situation means that uncertainty contributes to making complicated issues more complex as more and more interfaces (e.g. multiple experts) are created [5]. Making a complex decision therefore also involves making an uncertain decision.

The current tools and methods for risk management seem to be inadequate, given the complexity of the technology-driven industry [25]. Furthermore, the perceived need for a systematic approach to risk management is highlighted in these seemingly unstructured existing methods of risk management. The unique approach to risk management in a technology-driven industry is similar to the nature of technology: it should incorporate a structured but innovative approach to obtaining stakeholder acceptance.

A common way to gain understanding of a complex system is to analyse it (to make sense of a system by breaking the system apart into its sub-systems) [26, 27, 23, 28]. Analyses, however, focus on the elements of a system in isolation, and therefore lose the relations between parts. Systemic thinking combines analysis (simplifying systems by taking them apart into less complicated sub-systems) and synthesis (making sense of system components by seeing how they fit together and what their relations and interactions are with other system components) [27]. Analytical thinking is used to identify the elements; synthetical thinking is used to find the repeating pattern [27].

Figure 1 is a visualisation of systemic thinking in the process plant environment - such as that found in the cement production process case study considered in the next section - by breaking a plant into its various sub-systems up to the component level. It also indicates how components, areas or units, and equipment fit together in the plant from a system point of view.

Adjustments to a component or the functionality of a sub-system cannot be restricted to the sub-system or component. An example provided by Pahl \& Beitz [22] is combined coupling (comprising a flexible coupling and a clutch). As 'combined coupling' it can be regarded as a system that within a machine, or by joining two machines, can be regarded as an assembly. This assembly can be considered as two sub-systems: a 'flexible coupling' and a 'clutch', which in turn can be divided into system elements, in this case components. It is also possible to consider the functional relationship where the system 'coupling' can be divided into the sub-systems 'damping' and 'clutching'. 


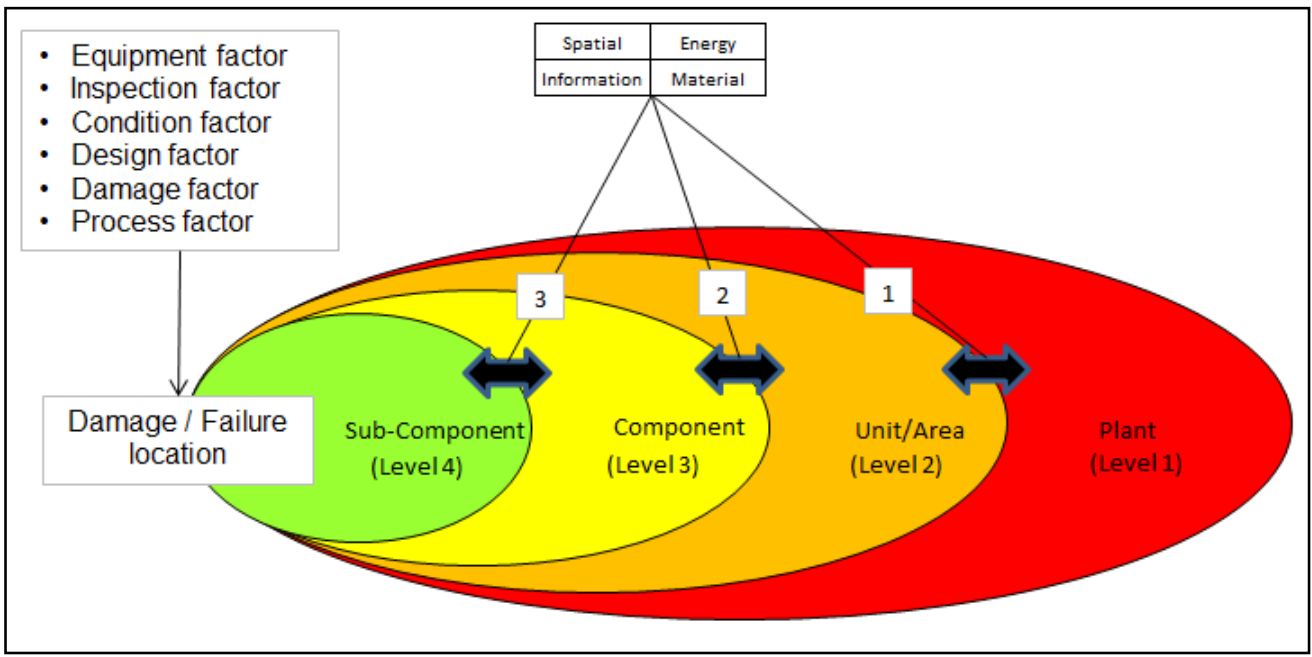

Figure 1: System visualisation (partially adopted from Takashi et al. [30])

To analyse the risk within such a system, one would have to analyse the interactions and relationships between components, machines, and plants within a system, for both the subsystem functionality and the sub-system requirements.

Eppinger \& Pimmler [30] consider system relationships along four dimensions, and evaluate the interaction between two system elements based on the conversion of energy, material, and information, and also their spatial orientation. Starting with the fundamental concepts of matter and force, one comes across matter in many shapes and forms; while a force applied to matter ultimately results in energy being transferred in different forms [22]. For the research presented in this paper, the interactions between components are considered along the following dimensions:

- Energy - mechanical, electrical, etc.

- Material - with characteristics such as mass, structure, composition, etc.

- Information - or signal exchange.

\section{DESIGN STRUCTURE MATRIX FOR RISK MANAGEMENT}

Throughout the engineering disciplines it is common practice for engineers to solve a complex problem by first breaking it into a set of smaller problems that are more easily handled. However, the decomposition of complicated systems can create challenges [30]:

- It might be difficult to break up the system into a suitable set of sub-systems.

- After decomposition it might be difficult to unite the various sub-systems into an overall system.

To overcome these challenges, an overall system functionality or system requirement can be decomposed into sub-system functionalities and sub-system requirements. Similar to the way in which designers establish particular systems and particular purposes by decomposing the system, the risks in a system can be decomposed into sub-risks of the sub-systems. This interaction suggests that a risk in a sub-system will interact with other sub-systems and also contribute to the risk in the total system. With reference to Figure 1, this risk-relationship can be visualised by realising that a failure of one of the two sub-systems in either mechanical construction ('flexible coupling' or 'clutch') or functionality ('damping' or 'clutching') will have an impact on the mechanical construction or functionality of the system ('combined coupling'), and in this case the assembly. By quantification of the relationship the impact can be established.

A system can, therefore, be decomposed into its various sub-systems, and by identification and quantification of risks within sub-systems (sub-risk), the system risk can be quantified. 
The methodology that is used in this research to represent and analyse dependencies and relations between items is known as the design structure matrix (DSM), and was introduced by Steward in 1967 [31] and in 1981 [32]. These papers are considered the origins of the DSM field. The major idea of Steward's approach was to handle uncertainty in complex systems by exploring the structure of a problem [25, 12]. Figure 2 illustrates, from the current research, where the DSM field can be used within the risk management process for risk identification, by identifying the relationship between system elements.

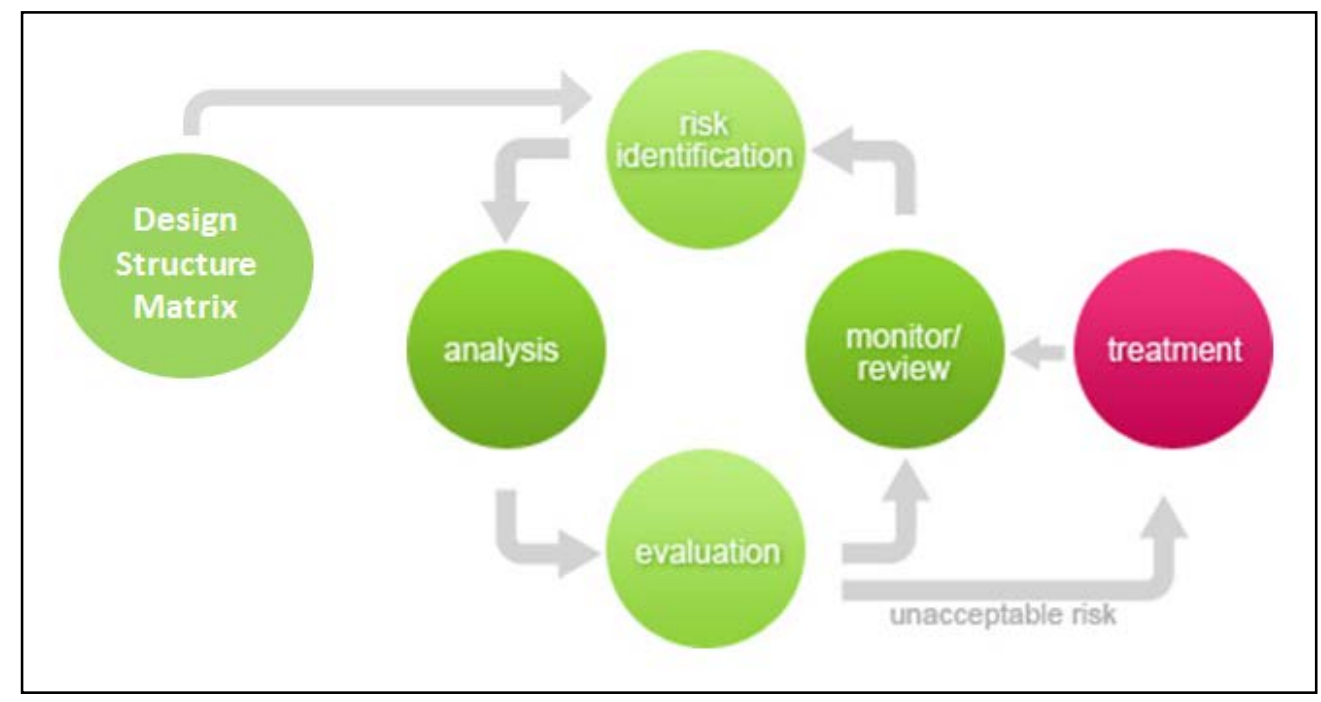

Figure 2: Design structure matrix within the risk management process

(partially adopted from Longfellows [33])

The introduction of the design structure matrix into the risk identification process (as illustrated in Figure 2), and making use of the quantification suggested by Eppinger \& Pimmler [30] to identify the interactions that may occur between the functional and physical elements, considers 1) associations of physical space and alignment, 2) associations of energy exchange, 3) associations of information (signal \& measurement) exchange, and 4) associations of materials (process) exchange.

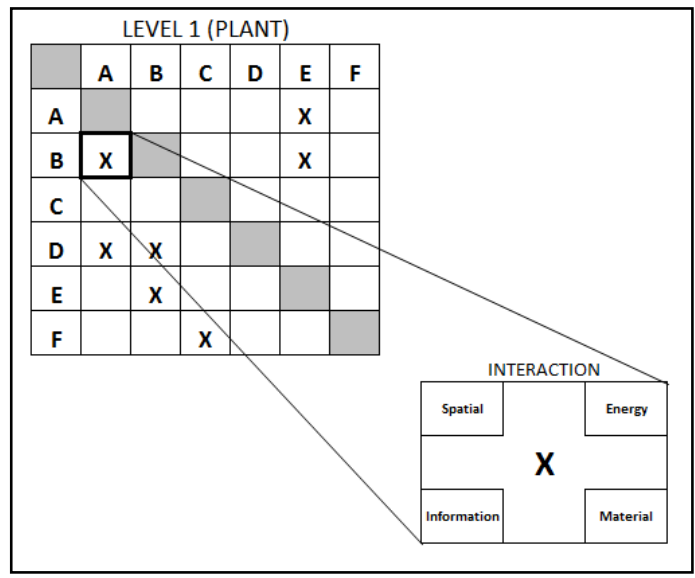

Figure 3: Interaction between elements, represented as a vector with four scores

For the purposes of this research, the interaction must be systematically identified to quantify and manage the risk of the complete system. Therefore, to identify, quantify, and manage the risks areas of a complete system, the risk areas of the various components and 
elements within the system must be systematically identified and quantified. Referring to Figure 3, the four generic interactions are defined as follows:

- "Spatial: A spatial-type interaction identifies the needs for adjacency or orientation between elements.

- Energy: An energy-type interaction identifies the needs for energy transfer between two elements.

- Information: An information-type interaction defines the needs for information, signal, or measurement exchange between two elements.

- Material: A material-type interaction identifies needs for materials exchange between two elements." [30]

The ranges of interactions used in this research are defined in Table 1.

Table 1: General interaction quantification scheme (partially adopted from Eppinger \& Pimmler [30])
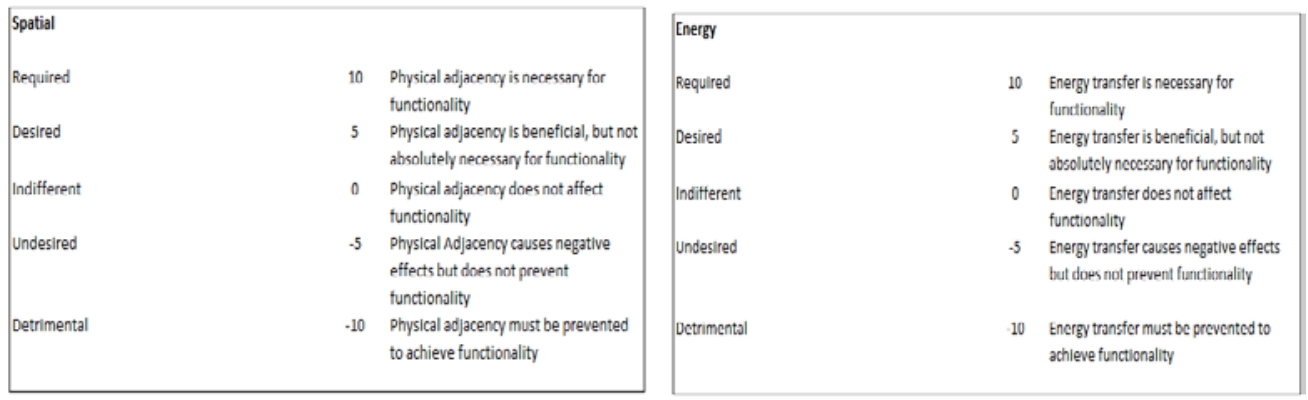

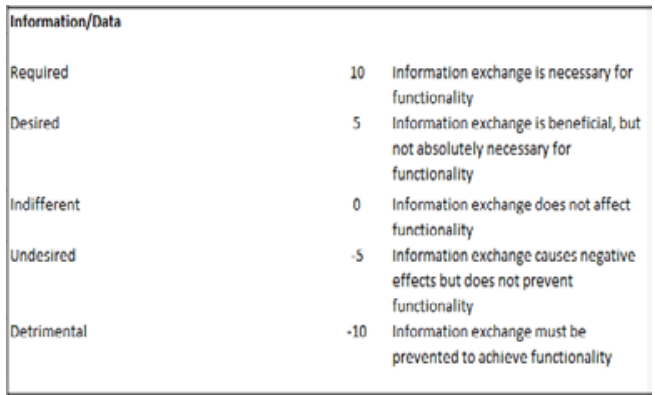

\begin{tabular}{|lll|}
\hline Moterial/Process & 10 & $\begin{array}{l}\text { Material exchange is necessary for } \\
\text { functionality }\end{array}$ \\
Required & 5 & $\begin{array}{l}\text { Material exchange is beneficial, but not } \\
\text { absolutely necessary for functionality }\end{array}$ \\
Indifferent & 0 & $\begin{array}{l}\text { Material exchange does not affect } \\
\text { functionality }\end{array}$ \\
Undesired & -5 & $\begin{array}{l}\text { Material exchange causes negative } \\
\text { effects but does not prevent } \\
\text { functionality }\end{array}$ \\
Detrimental & -10 & $\begin{array}{l}\text { Material exchange must be prevented } \\
\text { to achieve functionality }\end{array}$ \\
\hline
\end{tabular}

\section{FUZZY LOGIC FOR RISK MANAGEMENT}

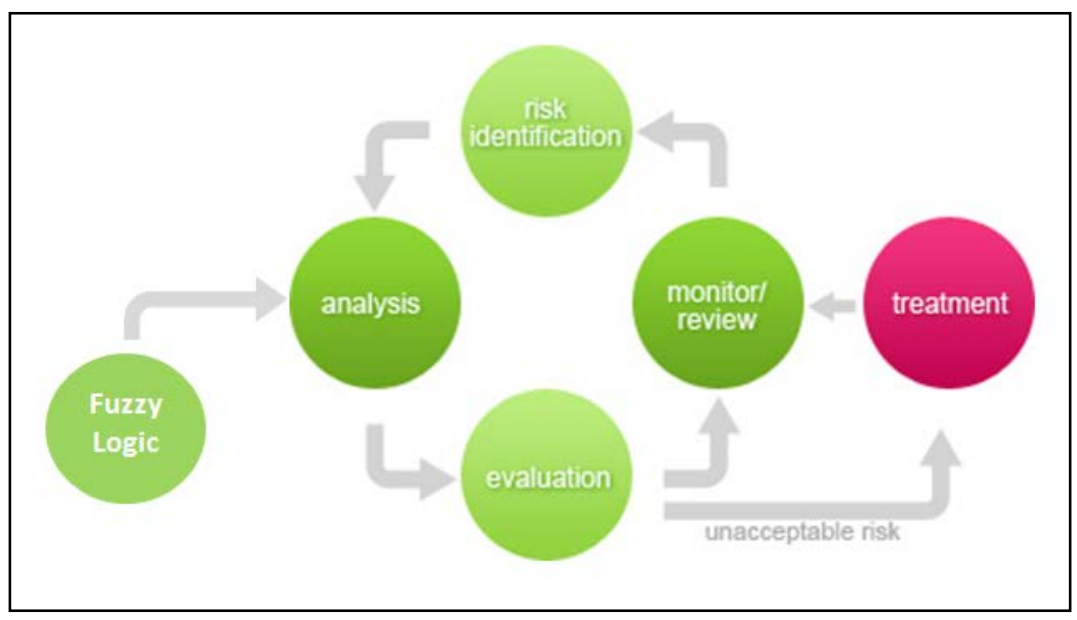

Figure 4: Fuzzy logic for risk management

(partially adopted from Longfellows [33]) 
The interactions of risk between elements are obtained by interviewing various system experts. In the case study introduced in the next section, the system experts were plant and process specialists. However, in evaluating this interaction it is difficult to provide a clear-cut definition of what interactions are 'HIGH', 'MEDIUM', or 'LOW'; such vagueness can be addressed in the fuzzy set theory [34, 35, 36]. All fuzzy rules apply at all times, and they apply in parallel. The fuzzy sets are converted to crisp output values by means of a process called defuzzification [37] - a process to get a non-fuzzy value that best represents the possibility distribution of an inferred fuzzy control action [38]. The selection of a defuzzification procedure depends on the properties of the application [39, 40, 41]. The weighted average defuzzification provides an acceptable accuracy with relatively simple mathematics [42].

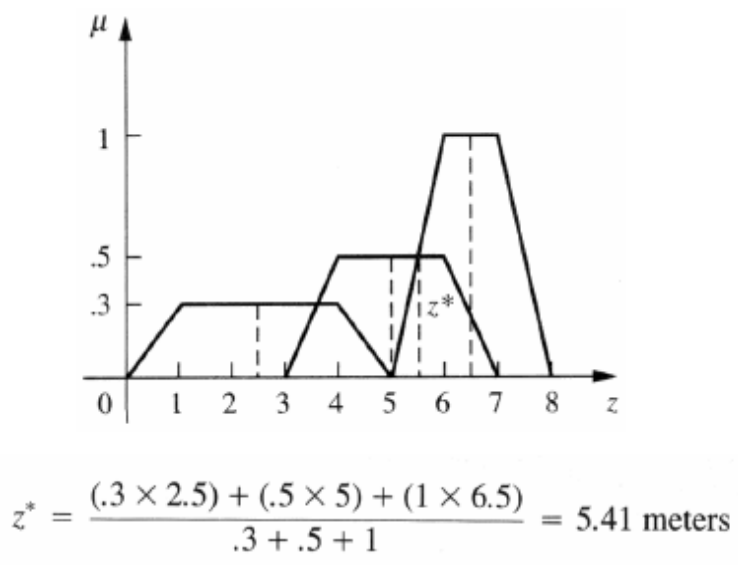

Figure 5: Weighted average defuzzification [43]

\section{CASE STUDY}

The lifeblood of a technology-driven industry consists of an organisation's ability to develop new products and to integrate risk management holistically, thus requiring risk management to be one of the concurrent tasks in the design process. By including risk management as a concurrent task in the design process, it creates the opportunity to develop the risk management model, following the same approach and principles used for product development. By adopting this developmental approach, a conceptual model and prototype was constructed as briefly described in the previous sections and evaluated using a case study.

With a focus on the cement grinding section of the cement process, and for the purpose of the case study, the following sub-systems of the cement grinding process were defined:

- Clinker transport

- Additives transport

- Finished product transport

- Recirculation transport

- Grits transport

- Mill drive

- Mill feeding

- Separator (and cyclones)

- System filter

- Hot fuel oil supply

- Hot gas generator

- Mill hydraulic

- Compressed air / cooling water 
The relationship and interactions between elements of the model referred to in the previous sections are obtained by interviewing the various system experts. In the case study, a small group of five plant experts were asked to complete a survey and provide a quantification of the interaction between plant components, based on their experience and the plant process. The survey used for the case study, and the results obtained from the survey, form part of a doctoral study presented at the ISEM conference in 2011 [44, 45]. After data collection and mapping of the interdependencies into the design structure matrix on the spatial, energy, material, and information levels, fuzzy logic is used to determine the overall interdependence between elements by applying the fuzzy rules chosen. A simplified version of the fuzzy controller is presented below for discussion purposes.

Chosen fuzzy rules:

- Rule 1: IF (Spatial is required) OR (Information is required) OR (Energy is required) OR (Material is required) THEN Risk Management Effort $=\mathrm{HIGH}$

- Rule 2: IF (Spatial is desired) OR (Energy is desired) OR (Information is desired) OR (Material is desired) THEN Risk Management Effort = MEDIUM

- Rule 3: IF (Spatial is indifferent) OR (Energy is indifferent) OR (Information is indifferent) OR (Material is indifferent) THEN Risk Management Effort = LOW

The following example values are chosen to illustrate the application of the fuzzy rules and the fuzzy controller output:

(Spatial, Information, Material, Energy) $=(5,7,2,1)$

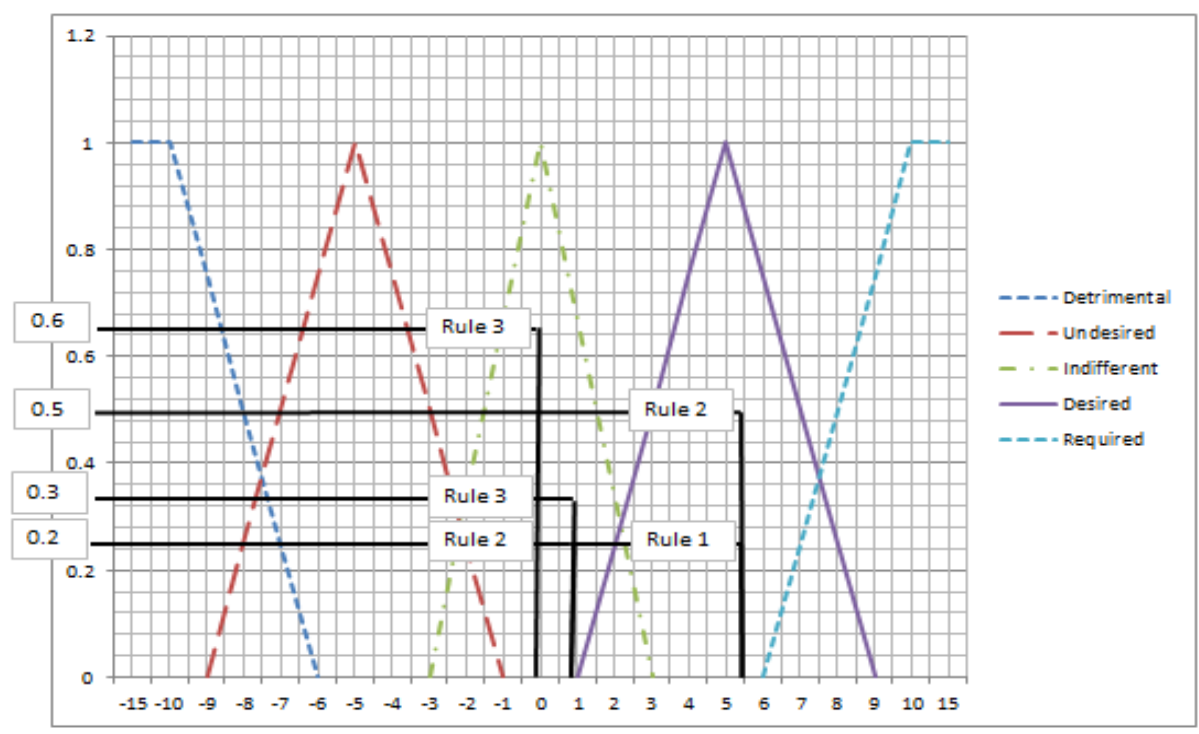

Figure 6: Application of rules in the fuzzy controller

For simplicity, the output set of the fuzzy controller is defined as a risk management effort that can be 'LOW', 'MEDIUM', or 'HIGH'. In Figure 6 the evaluation of Rule 1, Rule 2, and Rule 3 provides the following:

- Rule 1 Input is $\operatorname{MAX}(0,0.25,0,0,0)=0.25$ and Output is 6 (High)

- Rule 2 Input is $\operatorname{MAX}(0,0.25,0,0,0,0,0.5,0,0)=0.5$ and Output is 4 (Medium)

- Rule 3 Input is $\operatorname{MAX}(0,0,0,0,0.667,0.333,0)=0.667$ and Output is 2 (Low)

The output can be defuzzified using the weighted average formula illustrated in Figure 7:

Risk Management Effort $=((0.25 \times 6)+(0.5 \times 4)+(0.667 \times 2)) /(0.25+0.5+0.667)=3.41$ 


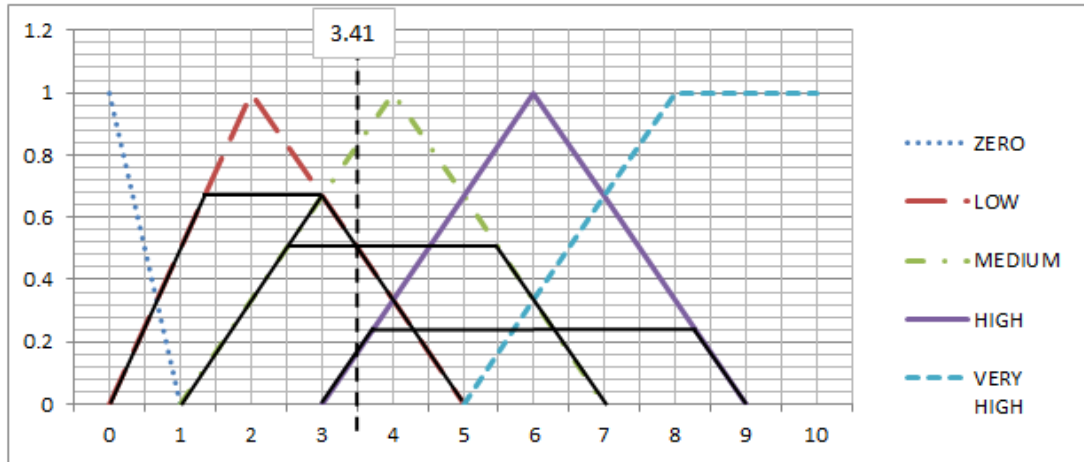

Figure 7: Fuzzy controller output (risk effort)

Table 2: Relationship rating

\begin{tabular}{|c|l|}
\hline Numeric scale & \multicolumn{1}{c|}{ Meaning } \\
\hline 0 & Zero risk management effort required \\
\hline 2 & Low risk management effort required \\
\hline 4 & Medium risk management effort required \\
\hline 6 & High risk management effort required \\
\hline 8 & Very high risk management effort required \\
\hline
\end{tabular}

The relationship rating for 3.41 classifies the risk management effort requirement as lying between Low and Medium (as defined in Table 2).

\begin{tabular}{|c|c|c|c|c|c|c|c|c|c|c|c|c|c|}
\hline & 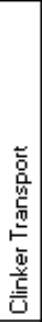 & 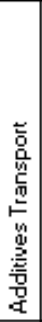 & 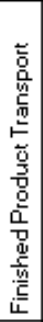 & 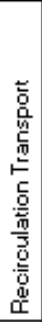 & 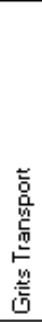 & $\begin{array}{l}\stackrel{0}{.} \\
\text { 点 } \\
\text { 衰 }\end{array}$ & 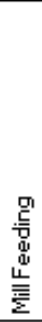 & 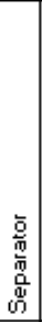 & 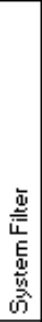 & 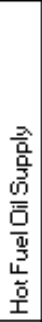 & 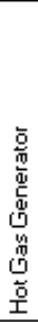 & 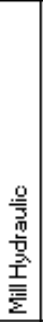 & 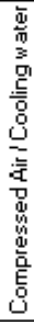 \\
\hline Clinker Transport & 0 & 0 & 0 & 0 & 0 & 0 & 0 & 0 & 0 & 0 & 0 & 0 & 0 \\
\hline Additives Transport & 0 & 0 & 0 & 0 & 0 & 0 & 0 & 0 & 0 & 0 & 0 & 0 & 0 \\
\hline FinishedProduct Transport & 0 & 0 & 0 & 6 & 0 & 0 & 0 & 6 & 0 & 0 & 0 & 0 & 0 \\
\hline Reciculation Transport & 0 & 0 & 6 & 0 & 6 & 8 & 0 & 8 & 6 & 0 & 0 & 0 & 0 \\
\hline Grits Transport & 0 & 0 & 0 & 5 & 0 & 0 & 0 & 5 & 0 & 0 & 0 & 0 & 0 \\
\hline Mill Drive & 0 & 0 & 0 & 4 & 0 & 0 & 6 & 5 & 5 & 0 & 0 & 4 & 0 \\
\hline Mill Feeding & 0 & 0 & 0 & 0 & 0 & 7 & 0 & 0 & 0 & 0 & 0 & 0 & 0 \\
\hline Separator & 0 & 0 & 5 & 5 & 5 & 5 & 0 & 0 & 0 & 0 & 0 & 0 & 0 \\
\hline System Filter & 0 & 0 & 0 & 4 & 0 & 5 & 0 & 0 & 0 & 0 & 3 & 0 & 0 \\
\hline Hot Fuel Dil Supply & 0 & 0 & 0 & 0 & 0 & 0 & 0 & 0 & 0 & 0 & 0 & 0 & 0 \\
\hline Hot Gas Generator & 0 & 0 & 0 & 0 & 0 & 0 & 0 & 0 & 3 & 0 & 0 & 0 & 0 \\
\hline Mill Hydraulic & 0 & 0 & 0 & 0 & 0 & 5 & 0 & 0 & 0 & 0 & 0 & 0 & 4 \\
\hline Compressed Air I Cooling w ater & 0 & 0 & 0 & 0 & 0 & 0 & 0 & 0 & 0 & 0 & 0 & 0 & 0 \\
\hline
\end{tabular}

Figure 8: Fuzzy controller output values represented in DSM

The resulting DSM from the defuzzification process (represented in Figure 8) will be a single matrix containing the combined weighted contributions (resulting from the fuzzy rules) from the four input DSMs (containing the components for spatial, information, material, and energy). The DSM can be manipulated using DSM tools such as clustering [11] to rearrange the DSM elements to obtain clusters of highly interacting components while minimising the inter-cluster interactions. During the clustering process, the data is not modified: matrix rows and columns are only swapped pair-wise (therefore also keeping the interrelationship between DSM elements) to obtain a different matrix layout. The new 
groupings or clusters represent a reorganised framework of the product architecture, visually showing the system elements that have the highest interaction.

The Cambridge Advanced Modeller by the Engineering Design Centre of the University of Cambridge is used in the research for DSM analysis and clustering (Refer to Figure 9 and 10) $[49,50]$.

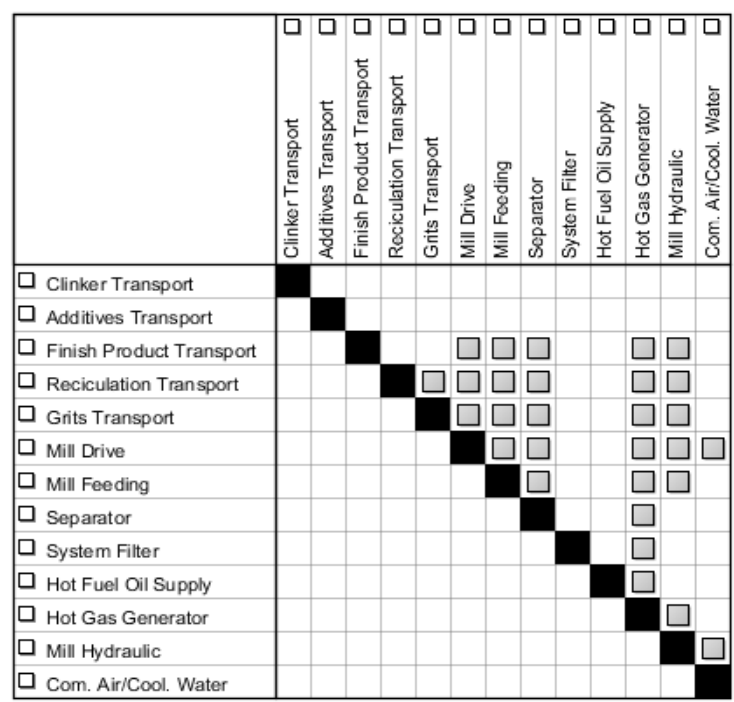

Figure 9: Output Matrix (CAM Representation).

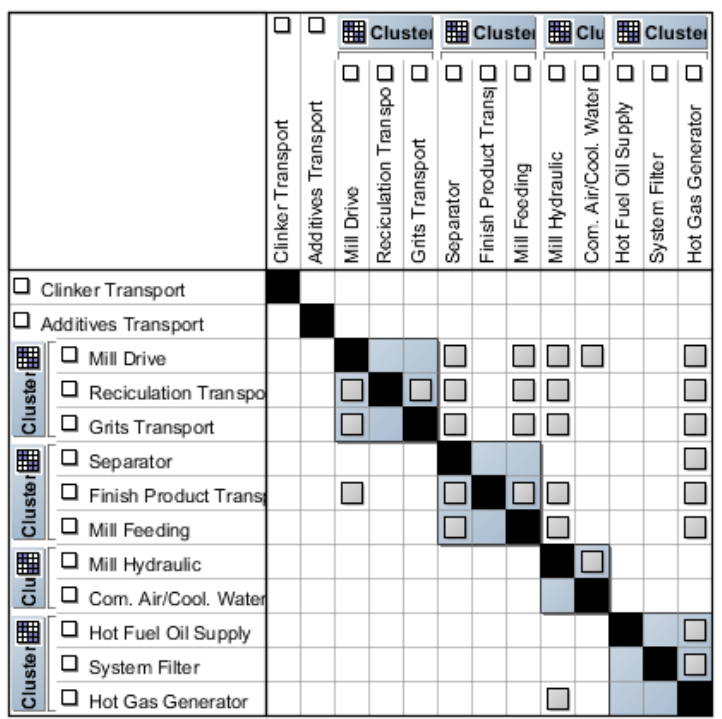

Figure 10: Clustered Output Matrix

When the DSM elements represent design components (i.e. component-based DSM) the purpose of the matrix manipulation becomes the finding of compartments of DSM elements (i.e. clusters or modules) that are mutually exclusive or marginally interacting subsets that is, clusters as groups of elements that are interconnected among themselves to an important extent while being little connected to the rest of the system [46, 47]. In the risk management domain, clustering of the system highlights risk areas in the system. Clustering of the matrix is similar to the application of Finite Element Method (FEM) or Finite Element Analysis (FEA) where a detailed visualisation of bending or twisting in structures is provided 
[48]. The clustering provides a visualisation of the high interaction areas within a system, and thereby 'risk stresses' (Refer to Figure 11).

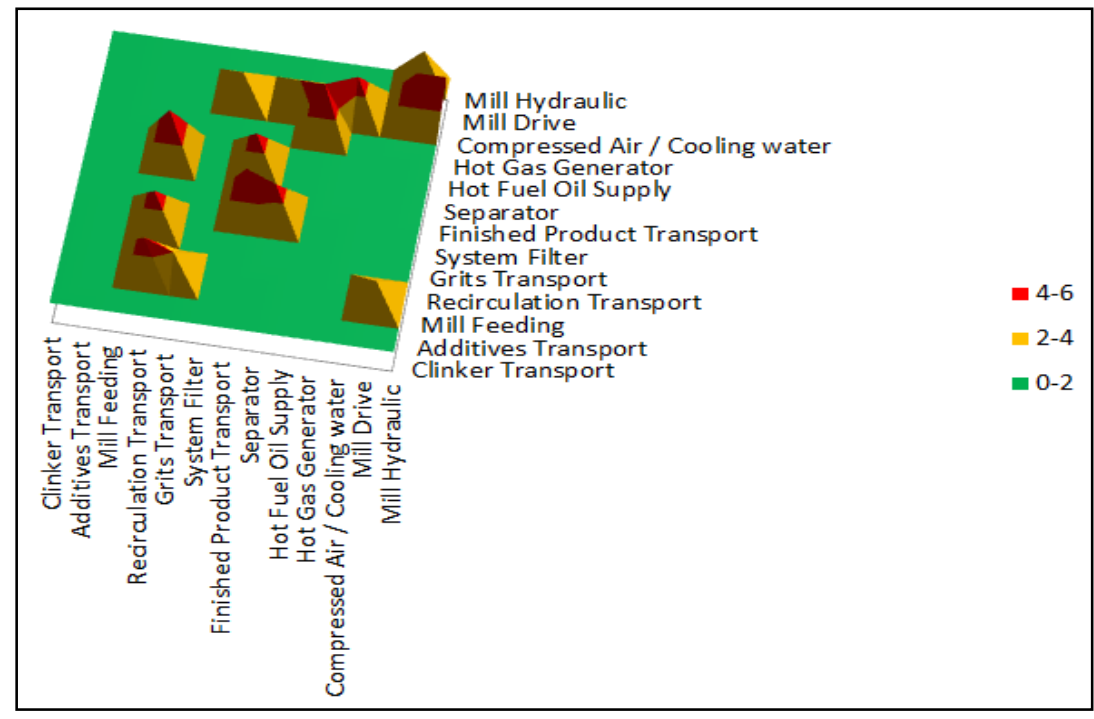

Figure 11: Risk management effort

\section{CONCLUSION}

Technology-driven industry can be very complex, due to its multi-dimensional characteristics and concurrently running tasks. One of the most efficient ways to approach complex problems is to follow a systematic approach and study the underlying structure of the complex system. In most instances, however, the analysis of a system (breaking the system apart) focuses on the elements of the system in isolation, and the relations between sub-systems are lost. This separation between sub-systems during analysis requires a systemic approach that will combine the analysis of the system with synthesis of the system. This therefore suggests a methodology where the complex system is broken into meaningful sub-systems without losing relations between the sub-systems.

An evaluation of the various risk identification and analysis techniques highlighted a lack in their ability to account for dependencies and relationships between system components. The methods that consider the relationships between system components (e.g. FMEA) are cumbersome. Tools and techniques are required for system decomposition and integration.

The DSM instrument was used to model the system and visualise the risk relationship between system components in various dimensions (spatial, material, information, energy). The DSM representation of the system allowed for systemic interpretation of the system by breaking the system into its sub-systems, while still keeping the relationship between the sub-systems, thereby establishing one of the key contributions of the research.

Risk management involves factors that defy classification into crisp sets, and the quantification of risk varies among different individuals and groups, based on their perception and experience. In the case study it was shown successfully that fuzzy logic can define values between the conventional digital logic (' $O N$ ' and 'OFF' or ' 1 ' and ' 0 ') providing a more human way of thinking. The input to the decision-making logic (the fuzzy logic rules) is based on a human expert knowledge base, and mimics how experts solve problems. It also makes a fuzzy logic controller fit comfortably into the risk analysis process.

The research presented here successfully integrates alternative system representation and analysis techniques [51]. In particular, the design structure matrix and fuzzy logic quantify 
the risk management effort necessary to deal with uncertain and imprecise interactions between system elements. As a further and final contribution, the matrix format of the clustered DSM provides a graphical overview of the system risk, highlighting high risk stress areas similar to the methodology used in finite element analysis (FEA).

The approach outlined in this paper provides a plausible approach to managing risk in a technology-driven industry. Further opportunity for refinement of the method is recommended through research. Particular areas of interest are the introduction of fuzzy logic controller feedback to incorporate risk treatment and monitoring, application to project risk management, and expanding the DSM to a Domain Mapping Matrix (DMM).

\section{REFERENCES}

[1] Bernstein, P.L. 1998. Against the Gods: The remarkable story of risk, John Wiley \& Sons.

[2] Berman, S.J . \& Hagan, J . 2006. How technology-driven business strategy can spur innovation and growth, Strategy and Leadership, Vol. 34 (2).

[3] Byrd, J \& Brown, P.J . 2003. The innovation equation: Building creativity and risk taking in your organization, Wiley.

[4] Bieri, S. 2001. Disaster risk management and the systems approach. [Cited June 20, 2010.] http://www.drmonline.net/drmlibrary/systems.htm.

[5] Van Asselt, M. B.A. 2000. Perspectives on uncertainty and risk, Kluwer.

[6] Harris, K. 1995. Collected quotes from Albert Einstein. [Cited August 27, 2010.] http://rescomp.stanford.edu/ cheshire/EinsteinQuotes.html.

[7] Anders, G. Who knew? Some of the predictions we made a decade ago were way off, The Wall Street J ournal, 9. [Cited February 20, 2010.]

[8] Adams, J. Risk Management: It's not rocket science... It's much more complicated. [Online]. [Cited February 8, 2010.]

http://www.rmmag.com/MGTemplate.cfm?Section=MagArchive\&NavMenulD=304

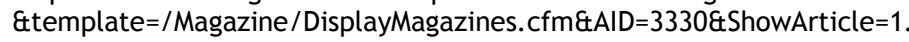

[9] Winzker, D.H. 2005. A holistic management model for the transformation of high technology engineering companies for sustained value creation and global competitiveness, Johannesburg: University of Johannesburg.

[10] Berman, S.J . \& Hagan, J. 2006. How technology-driven business strategy can spur innovation and growth, Strategy and Leadership, Vol. 34 (2).

[11] Yassine, A.A. 2004. An Introduction to modeling and analyzing complex product development processes using the design structure matrix (DSM) method. [Online] [Cited: 07 28, 2010.] http://users.ipfw.edu/reddpv01/DSMTutorial.pdf.

[12] Danilovic, M. \& Sandkull, B. 2005. The use of dependence structure matrix and domain mapping matrix in managing uncertainty in multiple project situations, International Journal of Project Management, Vol. 23, pp. 193-203.

[13] Cooper, D. R. \& Schindler, P.S. 2003. Business research methods, $8^{\text {th }}$ ed., McGraw-Hill Irwin.

[14] Childers, S.R. \& Long, J.E. 2000. A concurrent methodology for the systems engineering design process. [Cited August 3, 2010.] http://www.vitechcorp.com/ whitepapers/files/ 200611131842060.Long_Childers_1994.pdf.

[15] Conrow, E.H. 2004. Effective risk management, some keys to success, $2^{\text {nd }}$ ed., American Institute of Aeronautics and Astronautics.

[16] Gorrod, M. 2004. Risk management systems process, technology and trends, Palgraven Macmillan.

[17] J ames, M. 1995. Risk management in civil, mechanical and structural engineering, Proceedings of the conference organized by Health \& Safety Executive in co-operation with the Institution of Civil Engineers, held in London on 22 February 1995.

[18] Tippins, S.C. 2004. Risk management: Where is it and where does it belong?, Risk Management, Vol. 6 (3), pp. 9-11.

[19] Kusiak, A. 1999. Engineering design: Products, processes and systems, Academic Press.

[20] Gillow, K. 2005. A finite element method tutorial, Computational Biology Group: Finite Element Method Tutorial.

[21] Henderson, R.M. \& Clark, K.B. 1990. Architectural innovation : The reconfiguration of existing product technologies and the failure of established firms, FORM Global, Vol. 35, pp. 9-15.

[22] Pahl, G. \& Beitz, W. 1996. Engineering design: A systematic approach (edited by Ken Wallace and translated by Ken Wallace, Lucienne Blessing, and Frank Bauert), $2^{\text {nd }}$ ed., Springer.

[23] Sage, A.P. \& Rouse, W.B. 1999. Handbook of systems engineering and management, John Wiley \& Sons.

[24] Lindemann, P. 2009. The design structure matrix (DSM) http://www.dsmweb.org/. [Cited October 15, 2011.] 
[25] Danilovic, M. \& Browning, T.R. 2007. Managing Complex product development projects with design structure matrices and domain mapping matrices, International Journal of Project Management, Vol. 25 (2007) pp. 300-314, Elsevier.

[26] J ackson, M.C. 2004. Systems Thinking, John Wiley \& Sons.

[27] Wegmann, A. 2010. Systemic thinking. [Cited September 20, 2010.] http://lamspeople.epfl.ch/balabko/Professional/Systemic_Thinking/Index.htm.

[28] Li, C., Pretorius, L. \& Nel, A.L. 2006. Identifying risks by using a systems engineering approach: A technology management case study, IAMOT.

[29] Takahashi, J ., Node, T., Hatta, N. \& Fuji, A. 2003. Application of risk based maintenance to life and financial assessment at cement plants, Engineering Review, Vol. 36 pp.52-58.

[30] Eppinger, S.D. \& Pimmler, T.U. 1994. Integration analysis of product decompositions, Minneapolis, 1994

[31] Steward, D. 1967. The design structure systems, General Electric Report No. 67APE6, San Jose.

[32] Steward, D. 1981. The design structure system: A method for managing the design of complex systems, Transactions on Engineering Management, Vol. EM-28 (3), pp. 71-74.

[33] Longfellows. 2008. http://www.longfellows.com.au/images/risk_management_diagram.jpg. [Cited June 11, 2010.]

[34] Verworn, B. \& Herstatt, C. 2001. Managing the fuzzy front end of innovation, Working Paper, Department of Technology and Innovation Management, Technical University of Hamburg.

[35] Cheung, W.W.L., Pitcher, T.J. \& Pauly, D. 2005. A fuzzy logic expert system to estimate intrinsic extinction vulnerabilities of marine fishes to fishing, New Research and Expert Systems, Vol. 124 pp. 97-111,

[36] Mckone, T.E \& Deshpande, A.W. 2004. Can fuzzy logic bring complex problems into focus? Modeling imprecise factors in environmental policy, Lawrence Berkeley National Library.

[37] Zadeh, Lofti A. 1965. Fuzzy sets, information and control, Department of Electrical Engineering and Electronic Research Laboratory, University of California, Vol.8, pp. 338-353, Berkeley.

[38] Nissen, V. 2007. Management applications of fuzzy control, $52^{\text {nd }}$ Internationales Wissenschaftliches Kolloquium, Technische Universität Ilmenau.

[39] Simoes, M.G. 2010. Introduction to fuzzy control, Colorado School of Mines - Engineering Division.

[40] Brulé, J.F. 1985. Fuzzy systems - A tutorial. http://www.austinlinks.com/Fuzzy/ tutorial.html.

[41] Kosko, B. 1993. Fuzzy thinking: The new science of fuzzy logic. http://www.intelligentsystems.info/classes/ee509.9.pdf. [Cited May 2, 2011.]

[42] Zadeh, L.A. 1968. Fuzzy algorithms, information and control, Department of Electrical Engineering and Electronic Research Laboratory, University of California, Vol.12, pp. 94-102, Berkeley.

[43] Ross, T.J . 2010. Fuzzy logic with engineering applications, $3^{\text {rd }}$ ed., Wiley.

[44] Barkhuizen, W.F., Pretorius, L. \& Pretorius, J.H.C. 2011. An integrated systems approach to risk management within a technology driven industry using the Design Structure Matrix and Fuzzy Logic, University of Johannesburg.

[45] Barkhuizen, W.F, Pretorius, L. \& Pretorius, J.H.C. 2011. An approach to innovation in risk systems, ISEM 2011 Proceedings.

[46] Browning, T.R. 2001. Applying the design structure matrix to system decomposition and integration problems: A review and new directions, IEEE, Transactions on Engineering Management, Vol. 48.

[47] Aravind, H., Rajgopal, C. \& Soman, K.P. 2010. A simple approach to clustering in excel, International J ournal of Computer Applications, Vol.11, pp. 19-25.

[48] Eriksson, K., Estep, D., Hansbo, P. \& J ohnson, C. 1995. Introduction to adaptive methods for differential equations, Acta Numerica, pp. 105-158.

[49] University of Cambridge. 2011. Cambridge Advanced Modeller (CAM).

[50] Biedermann, W., Browning, T., Eppinger, S., Kreimeyer, M. \& Maurer, M. 2009. DSMweb. http://www.dsmweb.org/. [Cited August 1, 2011.]

[51] Warfield, D., 2005. IS/IT research: A research methodologies review, J ournal of Theoretical and Applied Information Technology, pp. 28-35. 